\title{
A retrospective study to analyse the ocular morbidity in the slum- dwelling population of central India
}

\author{
Shrivastava P. ${ }^{1}$, soni A. ${ }^{2}$, kumar $\mathrm{S}^{3}$, shrivastava L. ${ }^{4}$ \\ DOI: DOI: https://doi.org/10.17511/jooo.2021.i04.03 \\ 1* Poorva Shrivastava, Senior resident, , Gandhi medical college, Bhopal, Madhya Pradesh, India. \\ 2 Apoorva soni, Senior resident, , Gandhi medical college, Bhopal, Madhya Pradesh, India. \\ 3 Salil kumar, Ex-consultant, ophthalmologist, Gandhi medical college, Bhopal, Madhya Pradesh, India. \\ 4 Lalit shrivastava, Consultant, ophthalmologist, Kamla Nehru Hospital, Bhopal, Madhya Pradesh, India.
}

Background: The study aimed to evaluate the prevalence of different ocular pathologies in the slum-dwelling population of central India and to find its correlations with socio-demographic factors. Methodology: The study was conducted as a cross-sectional study in 84 slum areas across Bhopal, Jabalpur and areas in the vicinity using a camp-based approach during the study period of 3 years. A total of 15478 participants attended the camp, and of them, 6177 patients had various ophthalmological conditions. A detailed history was obtained, and participants were subjected to a complete ophthalmological examination. Based upon their diagnosis, they were prescribed treatment. Referral to the tertiary care centre was done when needed. Results: The prevalence of ocular morbidities was $39.9 \%$. The most common ocular morbidity documented in our study was refractive errors $(22.7 \%)$. Proportions of lid pathologies were significantly higher in patients belonging to less than ten years of age (36.4\%). In contrast, refractive errors were observed in higher proportions of patients belonging to more than ten years of age $(p<0.05)$. Pterygium ratio was significantly higher in males, whereas ocular malignancies were higher in females $(p<0.05)$. Proportions of almost all the ocular morbidities were substantially higher in patients with low socioeconomic status $(p<0.05)$. Conclusion: The overall prevalence of ocular morbidities in the slum population is high. The most common ocular morbidity includes refractive error and allergic conjunctivitis. These morbidities correlated with age, gender and socioeconomic status. We recommend periodic screening of the slum population across all age range to prevent long term complications and disabilities.

Keywords: Ocular morbidity, Slum, Refractive errors, Age, Socioeconomic status

\section{Corresponding Author}

Poorva Shrivastava, Senior resident, , Gandhi medical college, Bhopal, Madhya Pradesh, India. Email: poorvashrivastava1995@gmail.com
How to Cite this Article

Poorva Shrivastava, Apoorva soni, Salil kumar, Lalit shrivastava, A retrospective study to analyse the ocular morbidity in the slum-dwelling population of central India. Trop J Ophthalmol Otolaryngol. 6;4(2021):69-74.

Available From

https://opthalmology.medresearch.in/index.php/jooo /article/view/202
To Browse

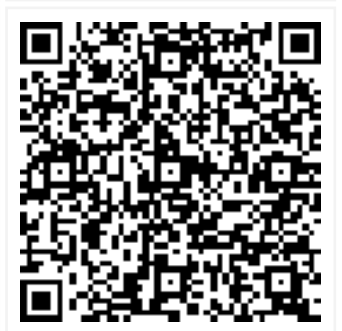
/article/view/202

Manuscript Received 2021-07-08

Conflict of Interest $\mathrm{Nil}$

Review Round 1
2021-07-10
Funding
Nil

Review Round 2
2021-07-17
Ethical Approval
Yes

Review Round 2

Yes

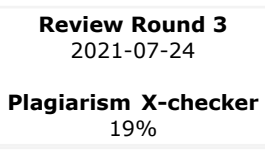

Accepted 2021-07-31

Note

(c) 6by Poorva Shrivastava, Apoorva soni, Salil kumar, Lalit shrivastavaand Published by Siddharth Health Research and Social Welfare Society. This is an Open Access article licensed under a Creative Commons Attribution 4.0 International License https://creativecommons.org/licenses/by/4.0/ unported [CC BY 4.0]. 


\section{Introduction}

The word "slum" for first used to describe the "room of low repute" or "low, unfrequented parts of the town" in the 19th century in London. However, the definition and its meaning have changed over time to include physical, social, spatial, and even behavioral aspects of urban poverty. [1,2]. According to United Nations, a Slum is defined as "one or a group of individuals living under the same roof in an urban area, lacking in one or more of the following five amenities, i.e. durable housing, sufficient living area, access to improved water, access to improved sanitation facilities and Secure tenure.[3].

The pattern of ocular morbidities among residents of the slum population may depend on overcrowding, unhygienic conditions, nutritional status, socioeconomic status, education, working conditions and health-seeking behavior. Ocular morbidity has been defined as any ophthalmologic pathology requiring clinical intervention or follow up.[4]. Overall, the prevalence of ocular morbidity in India has been reported to range between $20 \%$ and $90 \%$. [5-7]. Various ocular morbidities reported in India include Vitamin A deficiency, refractive error, conjunctivitis, amblyopia, strabismus, cataract, pterygium etc. [8]. Ocular morbidity may be one of the leading causes of visual impairment as well as preventable blindness. Literature suggests that approximately $85 \%$ of moderate to severe visual impairment and $80 \%$ of blindness is preventable and treatable.[9].

Data on the prevalence of ocular morbidities is primarily derived from hospital-based studies or institutions such as schools, blind homes etc. Community-based studies on ocular morbidities are lacking. The present study was therefore conducted to evaluate the prevalence of different ocular pathologies in the slum-dwelling population of central India and to find its correlations with sociodemographic factors.

\section{Methodology}

Setting- 84 slum areas across Bhopal, Jabalpur and areas in the vicinity using a camp-based approach

Duration and type of study - cross-sectional study during the study period of 3 years, i.e. from 1st June 2017 to 31st May 2021.
Sampling methods - Purposive sampling.

Inclusion criteria - All residents attending the camps and having various ophthalmological conditions were selected using universal sampling.

Exclusion criteria - All the participants not willing to participate in the study

Data collection procedure- A total of 15478 participants attended the camp, and of them, 6177 patients having various ophthalmological conditions were selected using universal sampling. Detailed data regarding socio-demographic variables such as age, gender, socioeconomic status etc., was obtained from all the study participants. They were subjected to a complete ophthalmological examination. Examination techniques included visual acuity assessment on Snellen visual acuity chart, torchlight examination, fundus examination in the cases in which it was strictly needed.

Based upon their diagnosis, they were prescribed treatment. Treatment strategies included refraction for the patients with refractive errors, prescription of eye drops and eye ointments, advice on lid hygiene, and referral to the tertiary care centre in the cases where the detailed examination was needed, such as in the case of suspected retinal pathologies like diabetic retinopathy, retinal detachment etc. Patients requiring surgical intervention for pterygium were referred to the tertiary care centre. Few cases of suspected ocular malignancies were also referred to the higher centre.

\section{Any scoring system- Nil}

\section{Surgical procedure if any- Nil}

Ethical consideration \& permission- the study was approved by the IEC committee of our institute

Statistical analysis- Data was compiled using MsExcel and analysed using IBM SPSS software version 20. Continuous data were expressed as frequency and proportions, whereas numerical data were expressed as mean and standard deviation. The Chi-square test was used to assess the correlations with various socio-demographic factors. A P-value less than 0.05 was considered statistically significant.

\section{Results}

In our study, a total of 15478 participants were 
Screened for ocular morbidities using a camp based approach in selected slums during the study period. Of them, 6177 participants had ocular morbidities. Thus, the prevalence of ocular morbidities was $39.9 \%$.

Table 1- Distribution of ocular morbidities according to socio-demographic variables

\begin{tabular}{|c|c|c|c|c|c|c|c|c|}
\hline \multirow{3}{*}{\multicolumn{2}{|c|}{$\begin{array}{c}\text { Socio-demographic } \\
\text { variables }\end{array}$}} & \multicolumn{4}{|c|}{ Ocular Morbidity } & \multirow{2}{*}{\multicolumn{2}{|c|}{$\begin{array}{c}\text { Total } \\
(n=15478)\end{array}$}} & \multirow{3}{*}{ value } \\
\hline & & \multicolumn{2}{|c|}{$\begin{array}{l}\text { Present } \\
(\mathrm{n}=6177)\end{array}$} & \multicolumn{2}{|c|}{$\begin{array}{l}\text { Absent } \\
(n=9301)\end{array}$} & & & \\
\hline & & n & $\%$ & n & $\%$ & n & $\%$ & \\
\hline \multirow[t]{4}{*}{ Age } & $0-10$ & 822 & 13.3 & 1849 & 19.9 & 2671 & 17.3 & \multirow[t]{4}{*}{0.001} \\
\hline & $11-30$ & 1351 & 21.9 & 2845 & 30.6 & 4196 & 27.1 & \\
\hline & $31-50$ & 2002 & 32.4 & 2386 & 25.7 & 4388 & 28.3 & \\
\hline & $>50$ & 2002 & 32.4 & 2221 & 23.9 & 4233 & 27.3 & \\
\hline \multirow[t]{2}{*}{ Gender } & Male & 3483 & 56.4 & 5772 & 62.1 & 9255 & 59.8 & \multirow[t]{2}{*}{0.001} \\
\hline & Female & 2694 & 43.6 & 3529 & 37.9 & 6223 & 40.2 & \\
\hline \multirow{3}{*}{$\begin{array}{l}\text { Socio-economic } \\
\text { status }\end{array}$} & Lower & 2873 & 46.5 & 3535 & 38 & 6408 & 41.4 & \multirow[t]{3}{*}{0.001} \\
\hline & $\begin{array}{l}\text { Lower } \\
\text { middle }\end{array}$ & 2178 & 35.2 & 3220 & 34.6 & 5398 & 34.9 & \\
\hline & Middle & 1136 & 18.4 & 2546 & 27.4 & 3682 & 23.8 & \\
\hline
\end{tabular}

The above table reveals ocular morbidities among residents of selected slums. The majority of participants belonged to the 31 to 50 years of age group (28.3\%), whereas ocular morbidities were present in maximum patients belonging to more than 30 years of age $(p<0.01)$. Similarly, the prevalence of ocular morbidities was significantly higher in males and residents of low socioeconomic status $(p<0.01)$.

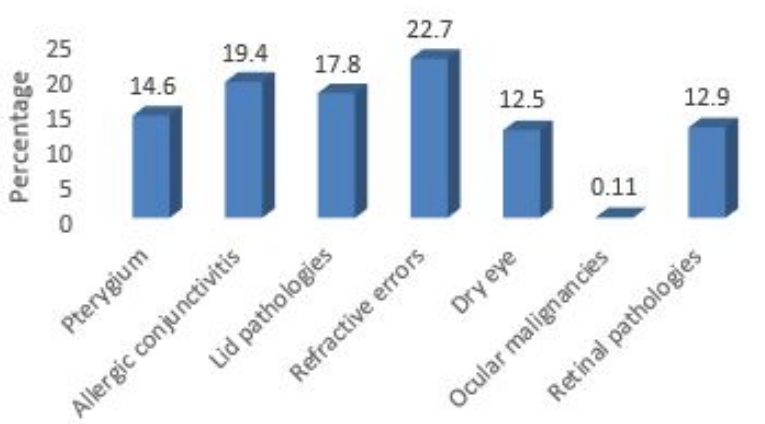

Figure 2: Distribution according to ocular comorbidities

The most common ocular morbidity documented in our refractive study errors was $22.7 \%$, followed by allergic conjunctivitis (19.4\%) and lid pathologies $17.8 \%$. The least common morbidity was ocular malignancy observed in $0.11 \%$ of cases.
Table 2- Association of age with ocular morbidities

\begin{tabular}{|l|l|l|l|l|l|}
\hline \multirow{2}{*}{ Morbidities } & \multicolumn{4}{|c|}{ Age (years) } & \multirow{2}{*}{ Total } \\
\cline { 2 - 6 } & $0-10$ & $11-30$ & $31-50$ & $>50$ & \\
\hline Pterygium & $0(0)$ & $150(16.7)$ & $400(44.4)$ & $350(38.9)$ & 900 \\
\hline Allergic conjunctivitis & $200(16.7)$ & $300(25)$ & $400(33.3)$ & $300(25)$ & 1200 \\
\hline Lid pathologies & $400(36.4)$ & $250(22.7)$ & $200(18.2)$ & $250(32.1)$ & 1100 \\
\hline Refractive errors & $150(2.6)$ & $350(19.5)$ & $450(38.96)$ & $450(38.96)$ & 1400 \\
\hline Dry eye & $20(2.4)$ & $150(11.1)$ & $300(14.98)$ & $300(14.98)$ & 770 \\
\hline Ocular malignancies & $2(28.6)$ & $1(14.3)$ & $2(28.6)$ & $2(28.6)$ & 7 \\
\hline Retinal pathologies & $50(6.25)$ & $150(18.8)$ & $250(31.25)$ & $350(43.8)$ & 800 \\
\hline P value & 0.001 & & & \\
\hline
\end{tabular}

The above table reveals that proportions of lid pathologies were significantly higher in patients belonging to less than ten years of age (36.4\%). In contrast, refractive errors were observed in higher proportions of patients belonging to more than ten years of age $(p<0.05)$.

Table 3- Association of gender with ocular morbidities

\begin{tabular}{|c|c|c|c|c|c|}
\hline \multirow[t]{3}{*}{ Morbidities } & \multicolumn{4}{|c|}{ Gender } & \multirow[t]{3}{*}{ Total } \\
\hline & \multicolumn{2}{|l|}{ Male } & \multicolumn{2}{|c|}{ Female } & \\
\hline & n & $\%$ & n & $\%$ & \\
\hline Pterygium & 550 & 61.1 & 350 & 38.9 & 900 \\
\hline Allergic conjunctivitis & 650 & 54.2 & 550 & 45.8 & 1200 \\
\hline Lid pathologies & 600 & 54.5 & 500 & 45.5 & 1100 \\
\hline Refractive errors & 800 & 57.1 & 600 & 42.9 & 1400 \\
\hline Dry eye & 430 & 55.8 & 340 & 44.2 & 770 \\
\hline Ocular malignancies & 3 & 42.9 & 4 & 57.1 & 7 \\
\hline Retinal pathologies & 450 & 56.3 & 350 & 43.7 & 800 \\
\hline$P$ value & 0.01 & & & & \\
\hline
\end{tabular}

In the present study, the proportions of pterygium were significantly higher in males, whereas ocular malignancies were higher in females $(p<0.05)$.

Table 4- Association of ocular morbidities with socioeconomic status

\begin{tabular}{|l|l|l|l|}
\hline \multirow{2}{*}{ Ocular morbidities } & \multicolumn{3}{|c|}{ Socioeconomic status } \\
\cline { 2 - 4 } & Lower & Lower middle & Middle \\
\hline Pterygium & $456(50.7)$ & $324(36)$ & $120(13.3)$ \\
\hline Allergic conjunctivitis & $547(45.6)$ & $443(36.9)$ & $210(17.5)$ \\
\hline Lid pathologies & $479(43.6)$ & $419(38.1)$ & $212(19.3)$ \\
\hline Refractive errors & $745(53.2)$ & $456(32.6)$ & $199(14.2)$ \\
\hline Dry eye & $300(38.96)$ & $247(32.1)$ & $223(28.96)$ \\
\hline Ocular malignancies & $4(57.1)$ & $2(28.6)$ & $1(14.3)$ \\
\hline Retinal pathologies & $342(42.8)$ & $287(35.9)$ & $171(32.4)$ \\
\hline Total & 2873 & 2178 & 1136 \\
\hline P value & 0.01 & & \\
\hline
\end{tabular}


The proportions of almost all the ocular morbidities were significantly higher in patients with low socioeconomic status $(p<0.05)$.

\section{Discussions}

The eyes are the most precious sense organ, which is essential for the normal physical and psychosocial development of an individual.[10]. Ocular morbidities can significantly affect visual acuity and may be responsible for partial or total blindness. Kumar et al. documented that approximately $30 \%$ of blind people in India lose their eyesight before 20 years of age, particularly in developing years of life ( $<5$ years).[11]. The cause of blindness may vary depending upon age and working conditions. The most common causes of blindness in children and the younger population include refractive errors, Vitamin A deficiency, trachoma etc. $[12,13]$. However, in middle age and elderly individuals, cataracts, glaucoma. Refractive errors and complications due to comorbid conditions are possible etiologies. $[14,15]$. Thus to prevent blindness, its associated complications and ocular disabilities, it is essential to detect these morbidities as early as possible.[10].

The present study was conducted camp-based research among the slum population belonging to any age group and either gender. A total of 15478 cases were enrolled belonging to the age range of 3 years to 78 years. The majority of participants belonged to 31 to 50 years ago. About $59.8 \%$ were males, and $41.4 \%$ belonged to low socioeconomic status. The prevalence of ocular morbidity in our study was $39.9 \%$. similar findings were documented by Khadse et al., in which the majority of ocular morbidities among the slum population was $40.4 \%$. [10]. Similarly, Gattani et al. demonstrated the prevalence of ocular morbidity in $42.3 \%$.[16]. In contrast, Aggrawal et al. reported ocular morbidities in higher proportions, i.e., $53 \%$, compared to the present study.[17]. The observed difference in the prevalence of ocular morbidities between the present study and the reference study could be attributed to the difference in health-seeking behavior of a population of two study areas.

Our study documented the prevalence of ocular morbidity significantly higher in middle-aged and elderly populations, among males and low socioeconomic status $(p<0.05)$. The spectrum of ocular morbidities in our study included
Refractive errors $(22.7 \%)$, allergic conjunctivitis $(19.4 \%)$, lid pathologies $(17.8 \%)$, pterygium $(14.6 \%)$, retinal pathologies $(12.9 \%)$, dry eye $(12.5 \%)$ and ocular malignancies $(0.11 \%)$. Previous studies documented similar findings. $[10,16,17]$. Gulati et al. [15]. Dandona et al. [18] documented a statistically significant association of ocular morbidities with advancing age, supporting the present study's findings. Khadse et al. documented presbyopia as the most common ocular morbidity in the slum population and established the association of ocular morbidities with advancing age.[10].

The present study also assessed the association of various ocular morbidities with various sociodemographic variables. We observed significantly higher proportions of lid pathology in extreme age, i.e., $<10$ and $>10$ years. Allergic conjunctivitis, pterygium was observed in significantly higher proportions of participants belonging to 31 to 50 years. The prevalence of refractive errors was observed across all age groups, but it was significantly higher in the middle-aged and elderly. However, the retinal pathologies were significantly higher in the elderly population. These findings could be attributed to age-related changes in the accommodative power of the lens as well as systemic comorbidities such as diabetes and hypertension leading to retinal pathologies. [19-21]. Our study findings were supported by findings of Agrawal et al., in which incidence of individual ocular morbidities, especially refractive errors, increased with advancing age.[22].

We observed a significantly higher proportion of ocular morbidities among males as compared to females. Overall, the proportion of pterygium, refractive errors, retinal pathologies, dry eye, allergic conjunctivitis and lid pathologies were significantly higher in males, whereas ocular malignancies were significantly higher in females. These findings were contrasting to the previous studies in which the prevalence of ocular morbidities was significantly higher in males than females. $[13,23]$. The present study also aimed to assess the association of socioeconomic status with ocular morbidities. We observed that ocular morbidities were significantly higher in participants from low socioeconomic status. This could be attributed to lack of awareness, poor health-seeking behavior due to fear of loss of daily wages, unhygienic conditions and overcrowding. Our findings were supported by the findings of Prajapati 
Et al. [12]. In which ocular morbidities were significantly prevalent in the participant of lower socioeconomic status.

This study had certain limitations. First, the study was conducted as a cross-sectional study; however longitudinal follow up study may have yielded a better result. Secondly, the patients requiring advanced investigations were referred to a higher centre, but the compliance of such patients remains unknown.

\section{Conclusion}

The overall prevalence of ocular morbidities in the slum population is high. The most common ocular morbidity includes refractive error and allergic conjunctivitis. These morbidities correlated with age, gender and socioeconomic status.

Author contribution: Dr Kumar and Dr L Shrivastava contributed to collecting and analysing the data of the patient who presented at the camps conducted across Bhopal. Dr P. Shrivastava participated and analysed in data collection and analysis of the patients presenting to the camps conducted across Jabalpur; she also analysed and observed significant correlations after the application of suitable statistical tests.

\section{What does this study add to existing knowledge?}

We recommend periodic screening of the slum population across all age range to prevent long term complications and disabilities.

\section{Reference}

01. Moreno, Eduardo López. Slums of the world: The face of urban poverty in the new millennium?: Monitoring the millennium development goal, target 11--worldwide slum dweller estimation. Un-Habitat, 2003. [Crossref][PubMed][Google Scholar]

02. United Nations Human Settlements Programme Staff. The challenge of slums: global report on human settlements, 2003. UN-HABITAT, 2003. [Crossref][PubMed][Google Scholar]

03. Habitat UN. State of the World's Cities 2006/7. New York: United Nations. 2006;292. [Crossref] [PubMed][Google Scholar]

04. Godbole M, Kavya NP,
Nekar MS, Bant DD. A cross sectional study to assess prevalence and pattern of ocular morbidity among pre-school children attending anganwadicentres of Hubballi taluk in South India. Int J Community Med Public Health 2019;6 (2):5459. DOI:10. 18203/2394-6040.ijcmph20190097 [Crossref][PubMed][Google Scholar]

05. Sharma $M$, Singh A. Pattern of treatment compliance among eye patients in a North Indian town. Ann Ital Chir. 2008 Sep-Oct;79(5):341-6. [Crossref][PubMed][Google Scholar]

06. Dalvi, S. D. , and P. V. Sathe. "Survey of ocular morbidity with special reference to senile cataract in rural population." Indian Journal of Preventive and Social Medicine 16.4 (1985): 103-10 [Crossref] [PubMed][Google Scholar]

07. Sehgal K, Kant L, Jain BK, Lal K. Prevalence of eye diseases in a semi-urban area. Indian J Public Health. 1984 Oct-Dec;28(4):189-93. [Crossref] [PubMed][Google Scholar]

08. Kemmanu V, Hegde K, Giliyar SK, Shetty BK, Kumaramanickavel G, McCarty CA. Prevalence of Childhood Blindness and Ocular Morbidity in a Rural Pediatric Population in Southern India: The Pavagada Pediatric Eye Disease Study-1. Ophthalmic Epidemiol. 2016 Jun;23(3):185-92. doi: 10.3109/09286586.2015.1090003 [Crossref] [PubMed][Google Scholar]

09. WHO. Global Data on Visual Impairements; 2010. Available from: http://www. who. int/blindness/GLOBALDATAFINALforweb.pdf. [Last accessed on 13th July 2021 [Crossref][PubMed] [Google Scholar]

10. Khadse, A. , Narlawar, U. , Humne, A. , Ughade, S. , \& Dhanorkar, A. Prevalence of ocular morbidities in an urban slum of central India. Health Sciences: International Journal, 4.1 (2014) 6-12 [Crossref][PubMed][Google Scholar]

11. Kumar, R. , Dabas, P. , Mehra, M. , Ingle, G. K., \& Saha, R. Kamlesh. Ocular morbidity amongst primary school children in Delhi. Health Popul Perspect Issues, 30.3 (2007): 222-9 [Crossref] [PubMed][Google Scholar]

12. Prajapati, P. , Oza, J. , Prajapati, J. , Kedia, G. , \& Chudasama, R. K. Prevalence of ocular morbidity among school adolescents of Gandhinagar district, Gujarat. Online Journal 
Of Health and Allied Sciences, 9.4 (2011) [Crossref] [PubMed][Google Scholar]

13. Dandona R, Dandona L. Childhood blindness in India: a population based perspective. $\mathrm{Br} \mathrm{J}$ Ophthalmol. 2003 Mar;87(3):263-5. doi: 10.1136/bjo.87.3.263 [Crossref][PubMed][Google Scholar]

14. Biradar, Somashekar P., and H. S. Arvind. "A study on industrial eye injuries." Journal of clinical and diagnostic research 5.5 (2011): 1076-1081 [Crossref][PubMed][Google Scholar]

15. Gulati N, Gupta NK, Jain BK, Gupta AK, Mehta SP. Some epidemiological aspects of ocular morbidity in a resettlement colony of Delhi. Indian J Public Health. 1987 Jan-Mar;31(1):60-70. [Crossref][PubMed][Google Scholar]

16. Gattani RG. A study of ocular morbid conditions in an urban slum community (Doctoral dissertation, Thesis for MD (PSM). Nagpur University, Nagpur). [Crossref][PubMed][Google Scholar]

17. Agrawal, D. , Singh, J. V. , Sharma, M. K., \& Mitthal, S. Ocular morbidity pattern of an urban population of Meerut. Indian J Prev Soc Med, 42.1 (2011): 74-8 [Crossref][PubMed][Google Scholar]

18. Dandona L, Dandona R, Srinivas M, Mandal P, McCarty CA, Rao GN. Unilateral visual impairment in an urban population in southern India. Indian J Ophthalmol. 2000 Mar;48(1):59-64. [Crossref] [PubMed][Google Scholar]

19. Khurana, A. K. Comprehensive ophthalmology. Jaypee Brothers Medical Publishers, 2019. [Crossref][PubMed][Google Scholar]

20. Nischal K, Pearson A, Jack J, Bowing KB; Clinical Ophthalmology, 7th edition, Library of Congress Cataloging in Publication Data, 2011. . Comprehensive ophthalmology. Jaypee Brothers Medical Publishers, 2019. [Crossref][PubMed] [Google Scholar] [Crossref][PubMed][Google Scholar]

21. Yanoff M, Duker J; Ophthalmology. 3rd edition, British library cataloging in publication Data, 2009. . [Crossref][PubMed][Google Scholar] [Crossref] [PubMed][Google Scholar] [Crossref][PubMed] [Google Scholar]

22. Agrawal D, Sahu A, Agrawal D. Prevalence of ocular morbidities among school children
In Raipur district, India. Indian J Ophthalmol. 2020 Feb;68(2):340-344. doi: 10.4103/ijo.IJO_1454_19 [Crossref][PubMed][Google Scholar]

23. Shrote VK; Study of ocular morbid conditions in the Rural field practice area of IGGMC. Thesis for M. D. , Nagpur University, Nagpur (P. S.M), 2006 [Crossref][PubMed][Google Scholar] 